\title{
Transformable building structures in architectural engineering education
}

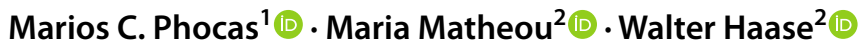

Received: 28 October 2021 / Accepted: 19 January 2022 /Published online: 4 February 2022

(c) The Author(s), under exclusive licence to Springer Nature Switzerland AG 2022

\begin{abstract}
In the last decade, various types of transformable building structures have been developed, such as deployable tensegrity, scissor-like and origami-inspired systems, as well as reconfigurable rigid-bar linkage and adaptive compliant structures. The development of the systems owns to advances in material design and kinetics, while aiming at an improved sustainability of the built environment. Their conceptualization and investigation have been enabled through associative parametric design and numerical analysis facilities that meanwhile provide robust digital visualizations and numerical analysis models. In principle, responsive building structures are capable to adapt to changing functional, loading, or environmental conditions. At university level, the integrated architectural design that involves an integrative development of the building form, functions and technical system parameters is increasingly enriched by performance-based design approaches through interdisciplinary experimentation and design-driven research, i.e., 'integrated interdisciplinary design', for the achievement of efficiency, sustainability and technological innovation in architecture. The paper discusses related influencing modes and preliminary design results of an integrated interdisciplinary approach driven by aspects of modularity, flexibility, transportability, deployability, adaptivity and interactivity, as well as their implications towards a framework of related research. The design projects presented have been supervised by the authors in recent years at the University of Cyprus and the University of Stuttgart. In all cases, the design methodology followed enables students to consider related morphological, functional and structural requirements, while being exposed to transformable building structures as related to aspects of materiality, functionality, sustainability and aesthetics.
\end{abstract}

Keywords Deployable structures $\cdot$ Reconfigurable structures $\cdot$ Compliant structures $\cdot$ Architectural design

\section{Introduction}

Marios C. Phocas

mcphocas@ucy.ac.cy

Maria Matheou

maria.matheou@ilek.uni-stuttgart.de

Walter Haase

walter.haase@ilek.uni-stuttgart.de

1 Department of Architecture, Faculty of Engineering, University of Cyprus, Kallipoleos St. 75, 1678 Nicosia, Cyprus

2 Institute for Lightweight Structures and Conceptual Design, Faculty of Civil and Environmental Engineering, University of Stuttgart, Pfaffenwaldring 7+14, 70569 Stuttgart, F.R., Germany

In achieving sustainability of our built environment, any contemporary technological advancement is expected to enable us to collaborate with nature, while being active agents. At architectural, tectonic level, sustainability is directly influenced by the materials, the structure and construction, the erection and the energy efficiency. Most importantly, sustainability derives from the syntax of design, that in some cases only enables flexibility according to the changing needs of the users and external conditions, as well as structural efficiency with minimum means and material. Acknowledging this fact, related principles of design, architectural features and optimization procedures have been applied in achieving adaptation and transformability of the buildings and their components. Transformability may help towards meeting certain objectives related to modifications of the building shape and floor area for improved space 
utilization, indoor acoustics, lighting conditions, sun protection, natural ventilation, photovoltaics energy efficiency, as well as reduced wind loading. Related initial concepts in architecture referred to the need of the built environment to be perceived on a modular basis, i.e., as composition of interconnected elements that acquire a transformative, evolving and interactive relationship with the users and the wider environment [1]. Subsequently, adaptation was favored through passive element and material attributes, i.e., building mass reduction and high strength materials of relatively low elastic modulus [2,3]. Moreover, the introduction of engineering principles for adaptation and transformability enabled architecture to adapt to differing functional, environmental or external loading conditions through systems with embedded actively controlled mechanisms [4]. Respective changing conditions are closely related to the transformation rate of the system. While slow transformations are associated with functional, environmental and energy input criteria, fast transformations are required in interactive environments. In fact, this attributes to a number of structural forms in achieving optimized structural response on one side, or even, intense experimental and experiential experience to the users on the other side.

Different typologies and kinetic systems have been developed in recent years for architectural and other engineering applications, primarily in relation to deployable, temporary structures [5]. Nonetheless, deployable structures are limited to specific target configurations, while transformable structures with enhanced flexibility and controllability may obtain different configurations in response to various contexts. Proposed systems enabling deployability refer to tensegrity [6, 7], scissor-like [8-10], origami inspired [11, 12], rigid-bar linkage $[13,14]$ and adaptive compliant structures $[15,16]$. Transformability is possible in tensegrity systems through direct implementation of linear motion actuators in place of compression members, or tension members of variable length [17-20]. In scissor-like systems increased configurations variability is enabled through additional application of simple angulated elements [10, 21], scissor-hinge mechanisms [22, 23], and universal scissor components [24]. In addition, origami structures of rigid plates form a combination of corresponding linkages, since faulting concentrates in the hinge-like creases that include the actuation mechanism [11]. In rigid-bar linkage structures, controlled transformability is achieved through actuator elements installed on the joints or the joint supports of the bar elements $[25,26]$. Finally, adaptive compliant structures of bending-active members may be activated for reversible deformations through actuation of the members or their supports, as well as through coupling of cables of variable length [27-29]. In all cases, actuation may be classified in four methods, namely motor-based, hydraulic, pneumatic and materialbased actuation [30]. The design and implementation of an actuation system is based on certain criteria related to the typology of the primary structure as well as the required flexibility and responsiveness to changing external conditions. In addition, the efficiency of the control system refers to the operation mechanism based on specific criteria of mechanics, the minimal amount of operational energy required for the transformation, as well as the operation of the structure.

Transformable buildings involve a relatively high level of complexity within the design process and planning expenditure, due to the integration requirement of complex technologies from mechanical engineering, control system technologies and computer science. Their design is based on physical models, digital simulations, numerical analysis and prototypes in providing insight to the designer in terms of geometry, kinematics and structural performance [31]. In particular, digital design modelling and automated numerical structural analyses provide visualization and feedback features that play a decisive role in the systems' development with regard to the form, material and structure. Thereby, designing becomes interdisciplinary towards form-generating processes and the development of prototype structures with actual transformability and adaptation for achieving an optimized and responsive behavior. The top-down and bottom-up approach in the design of transformable structures, as well as related kinematic issues are described in [32]. Embedded computation in architecture is described in [33] as a new design approach conducted at an interdisciplinary level that embraces technology from early stages of the design. By extension, the pedagogical approach to designing transformable structures gives rise to new designs and exploration [34]. While digital design and numerical analysis enable conceptualizations of transformable structures in terms of structural and control mechanisms, an encompassing theory of architectural design pedagogy that accommodates related design-driven research, thereby enhancing interdisciplinary performative processes, is also needed. [35]. Along these lines attributes of digital design, numerical investigations and transformational behavior investigation of the systems gain significance within an integrated architectural design process.

This paper presents the authors' integrated interdisciplinary design approach for the development of transformable structures to meet concrete objectives such as efficiency, sustainability and technological innovation. The pedagogical approach focuses on a nonlinear technology-driven design and analysis throughout different scales, from the element, to the system and building envelope scale. In all cases presented, the syntax of design is based on related aspects of low self-weight, high modularity, flexibility, easy transportability and expendability. It is noteworthy that an improvement of the structural operation and kinematics play a key role in response to related changing morphological, 
functional requirements of the building and external stimuli. The design methodology described in the next chapter is illustrated by students' design projects supervised by the authors in recent years at the University of Cyprus and the University of Stuttgart at various undergraduate and postgraduate levels. Furthermore, the selected design projects introduce at conceptual level, kinetic system typologies based on hybridization of the components with regard to their load-bearing behavior and kinematics that enable increased flexibility and controllability.

\section{Integrated interdisciplinary design}

Architectural design constitutes traditionally a project-based activity, whereas related social, cultural, visual and technological criteria are collected, analyzed, evaluated and applied within the process [36]. However, advances of disciplines, material, structural and computational technologies have significantly altered the contextual frameworks of architectural design and production. In consequence, the architectural design approach of form, functions and technical system parameters integration is increasingly enriched by performance based open-loop design approaches that involve an early interrelation and integration of technological aspects within.

Integrated architectural design is followed in multidisciplinary context of operation, whereas the integral development of the morphology, construction and energy efficiency is supported by the structure's development, Fig. 1. At the same time, the design vision and principal goals that interconnect the various design scales and levels of analysis serve as a connecting factor. Collaborators make decisions together based on a shared vision and a holistic understanding of the project. The term of integrated design refers to the design, planning, construction and operation of buildings and hence considers the entire building life cycle [37, 38]. The present paper deals with the preliminary design stage, in particular, that of the conceptual design. Application of the integrated design approach from early stages aims at achieving clearly articulated design prepositions, as well as increased efficiency and quality in the individual development areas involved [39]. In this framework, it is well acknowledged that the synthesis process is, by definition, the integration of separate elements to create a cohesive whole, implying that the whole is greater than the sum of the individual parts. Integrated architectural design facilitates merging of individual knowledge and interdisciplinary research-based knowledge, while enabling new knowledge inquiry and acquisition at various design stages that form closed-loops of the development process. During this process, the design team works in iterative loops, given that local changes might influence the global design and vice versa $[40,41]$. In principle, there is no fixed scale at which the design process is essentially to be developed, while all design parameters and stages are interdependent. Along these lines, digital design and numerical analysis platforms of operation provide the possibility not only to implement interdisciplinary collaboration and design integration from the outset, but also to shape and interconnect throughout the different stages of the design process, any individual iterative operational circles that are linearly linked to previous and subsequent ones [42]. In this way, an integrative nonlinear design process emerges, whereas, functionality, generality and interoperability are maximized.

The requirement for transformability influences from early stages the process of development through individual, or multiple interactive parameters within an integrated design context that needs to involve the disciplines of architecture, structural, mechanical and control engineering. In this framework, the development of transformability features may be decisive for the formulation of the architectural design syntax, and possibly further provide related designdriven technological developments. The process of conceptualizing, analyzing, and evaluating transformable systems is therefore based on advanced interdisciplinary research, which supports the integrated context of design even further. Alternatively, additional advanced research may be required for the realization of transformable design proposals, that would lead to further interdisciplinary design processes and
Fig. 1 Integrated architectural design approach

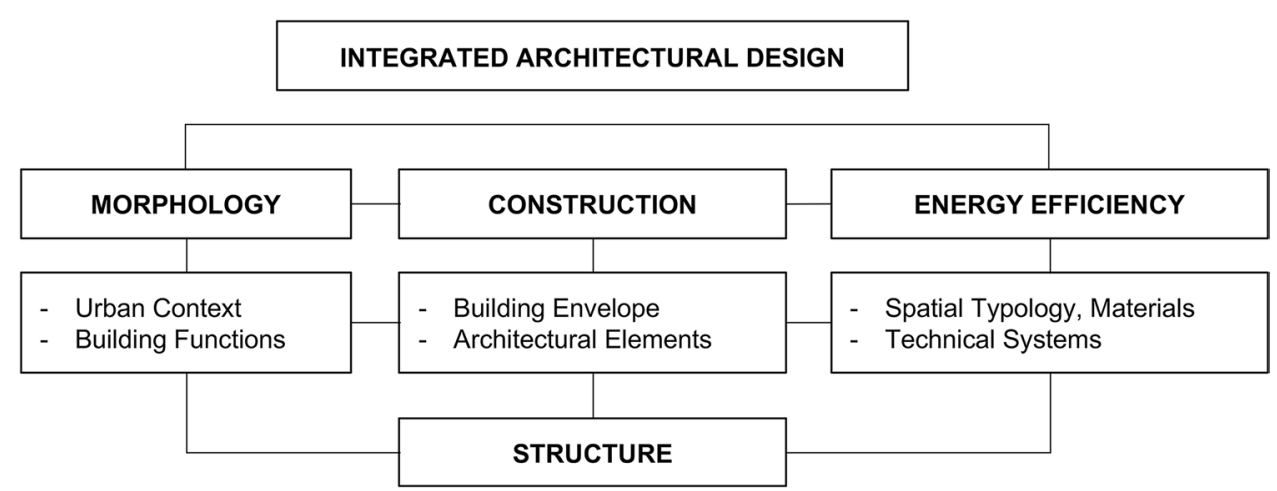


technological innovations. In both cases, interdisciplinary collaboration supports the transformable systems driven research processes within an integrated architectural design. Along these lines, the preliminary architectural design is jointly developed with the structural design, and includes the kinematics, the actuation principles and the actuators integration. This process requires an early involvement of various members and disciplines that provide their expertise according to the task and design goals employed throughout the process. By extension, the interpretation of the design into intermediate research results succeeds through the interdisciplinary teams that are continuously formed and reformed. The success of the methodology is based on an integrative approach to research of transformable structures in architectural design, which also examines the systems performance in producing sustainable forms in physical context.

Interdisciplinary performance-based design of transformable structures utilizes advances in digital technology and numerical analysis facilities in following open-loop processes of investigation and development. This mode of operation involves a synergistic architectural and engineering design approach, in terms of the structure composition, stability, kinematics and operation, as well as energy performance of the actuation system, Fig. 2. The process of development is cyclical nonlinear and includes related stages of development ranging from 'synthesis' to 'evaluation' and 'verification'. Thus, the design process is repeated until a desirable solution is achieved and refined within the performative context of re-evaluation. In parallel, interactivity within the individual interdisciplinary design steps may even yield a bottom-up approach of investigation with emphasis on the definition and optimization of influencing values and parameters within the process. Integrated interdisciplinary design may include such open-loop processes from early stages, in complementing individual knowledge by the members of the teams and research-based knowledge in cross-disciplinary context within the teams. By extension, the design benefits not only from the investigation and implementation of synergistically developed transformable systems, but also from the possibility that collaboration may trigger the ability to envision and research from a transformable-systems thinking perspective.

The pedagogical framework for integrated interdisciplinary design is applied throughout the development of the students' design projects shown in the next chapter, relying on physical modeling, digital simulations, and analysis in interactive architectural-engineering environments. An initial investigation of the architectural specific requirements of the brief is followed in each case by the formulation of a general proposal on the capability of the building to transform, in order to accommodate the primary design vision set. In this stage, brief lectures are given by the tutors and reviews are conducted by the students on the basics of kinetic design principles. In following, the integrative development of the architectural concepts and the implementation of transformability features at conceptual level enables a qualitative assessment of morphological, structural and environmental criteria, i.e., the synthesis, and defines further related interdisciplinary developments required, including evaluation and verification of the initial technological
Fig. 2 Interdisciplinary transformable building structures design methodology

\section{TRANSFORMABLE STRUCTURES DESIGN PROCESS}

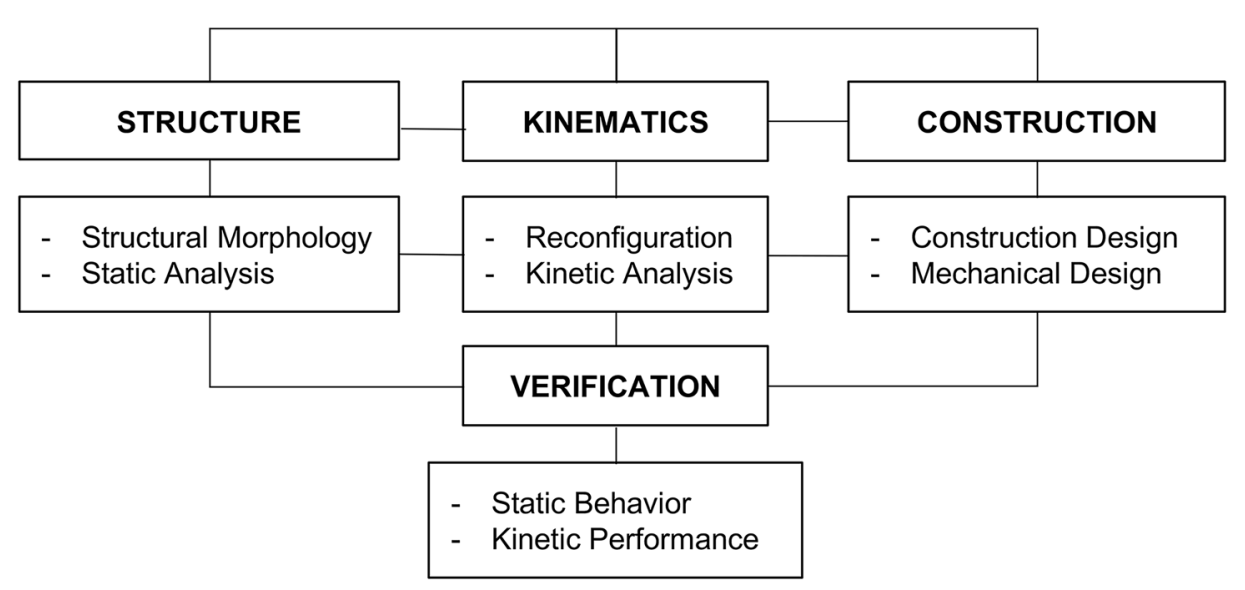

Interdisciplinarity

Architecture / Structural Engineering

Robotics / Kinematics / Control 


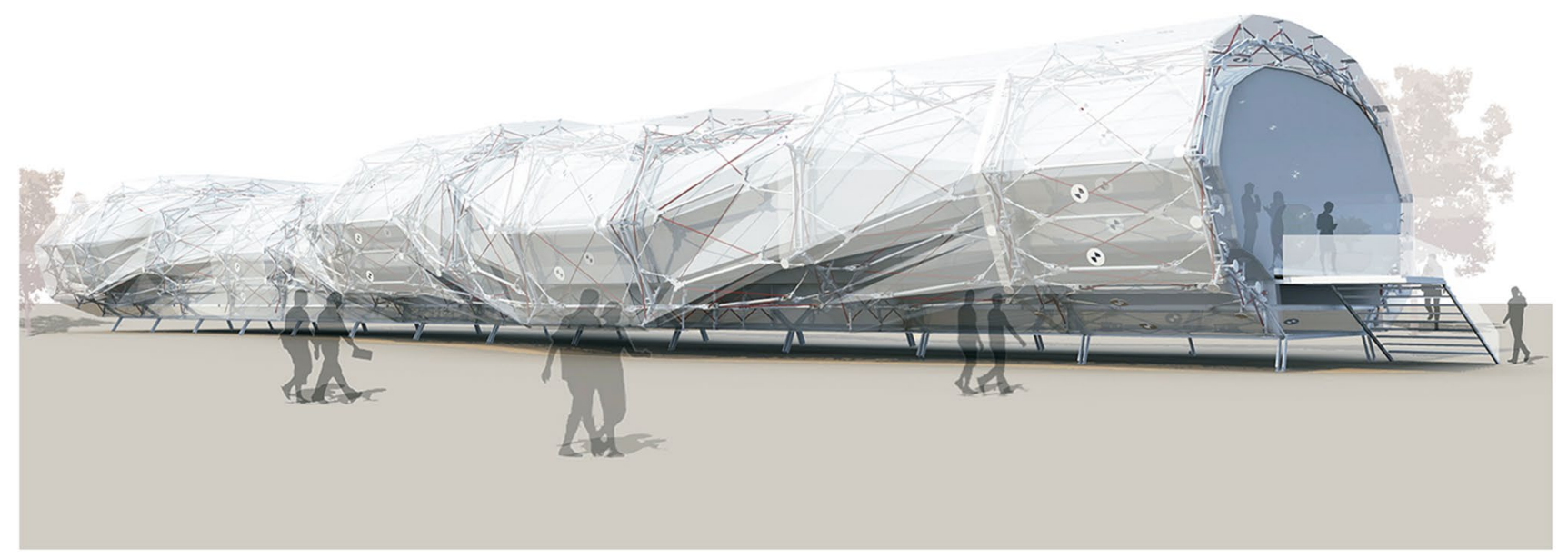

Fig. 3 Perspective view of the building [S. Anastasiou, S. Theologou and M. Christofi]

visions set. The development of the initial architectural concepts involves open-loop performance-based processes of investigation and development from a structural and kinematics point of view. As the projects unfold, a diverse team of supervisors is gradually added to the core disciplines of architecture, structural and mechanical engineering. The add-on collaborators include "specialists" from other Institutes and Departments of the University, the industry or other research institutions that contribute to the development through their individual knowledge transfer and exchange within the research-driven design process. Thus, the teams may be continually formed in a cyclical process of different design stages. This framework enhances interdisciplinarity in two ways: in the designs' development from the students' perspective, in terms of forming sub-groups with similar design aims but leading to different transformability features, and in the process of supervision, collaboration and evaluation of the designs by the supervising teams.

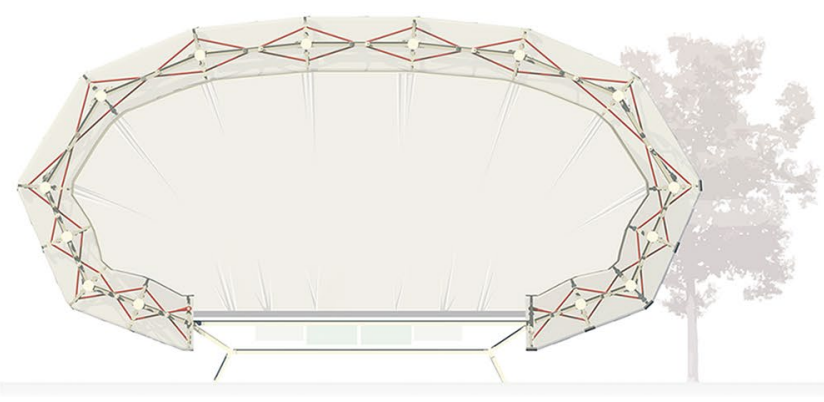

\section{Transformable structures designs}

\section{Hybrid Bar linkage structure}

The design of a Research Center for Advanced Mobility Technologies refers to an international research platform of fundamental and applied research with regard to environmental issues and alternative mobility ways, Fig. 3 . The building has a total area of approximately $2000 \mathrm{~m}^{2}$ and envisages to provide adaptable, flexible spaces, where different researchers may work at different time periods, Fig. 4. The building reflects its interrelated functional areas with the construction and energy efficiency and provides a focal point of research and technological advancements.

The spatial structure is articulated as of interconnected planar modular systems. The planar systems comprise 9-bar linkages that are supported by a secondary system of struts and continuous cables of variable length, Fig. 5 . The struts of rectangular hollow sections are divided at mid-length and interconnected through steel plates that pass through

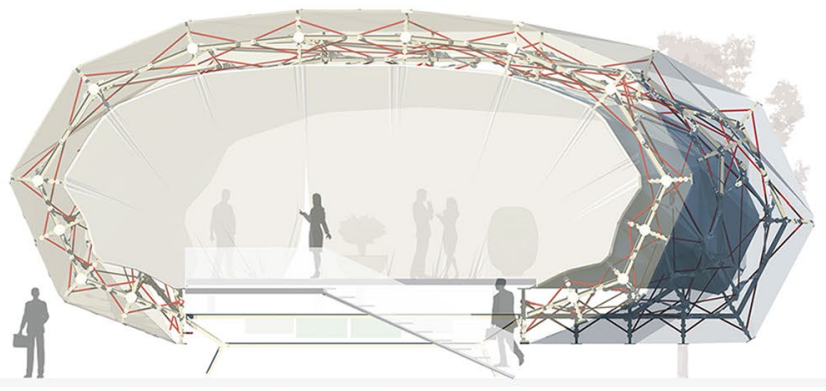

Fig. 4 Building sections in a symmetric and nonsymmetric structure configuration 

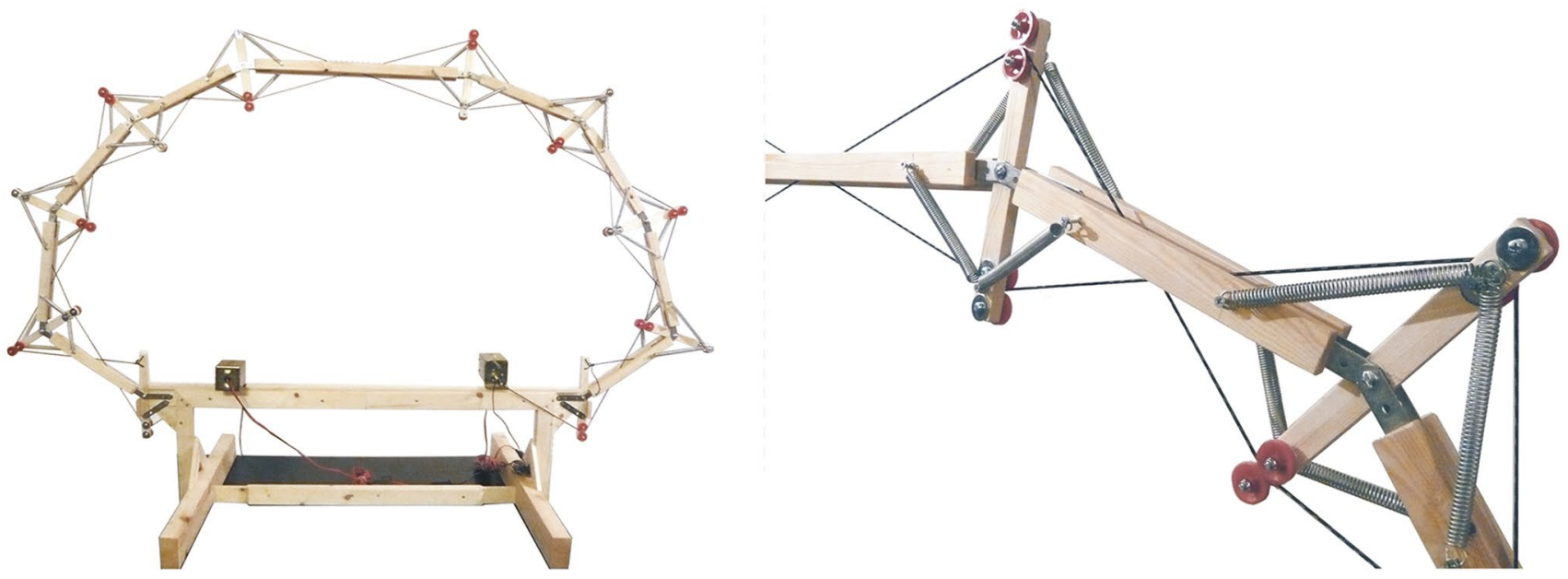

Fig. 5 Small-scale model of the hybrid structure

the joints of the rigid bars of double UPN sections joined together back-to-back. Diagonal spring elements connected between the bars and the struts are responsible for the selfcentering of the struts following each joints angle change. The cables are responsible for the actuation of the planar systems. Thus, the operability of the structure primarily relates to its integrative composition and the dual function of the secondary system with regard to the system's stability and kinematics. The planar systems are interconnected in the longitudinal direction through secondary telescopic members and continuous cable diagonals of variable length in accommodating any relative configuration differences between the primary planar linkages. Following the reconfiguration process, the horizontal members are locked in length, in order to ensure the diaphragm on the periphery of the spatial structure. In principle, expandability of the spatial structure is straightforward along all three directions. Given the modularity of the structure, each linkage can be augmented with additional members, but also the spatial structure can be expanded in the longitudinal direction with additional linkages.

Reconfigurations of the pin supported planar systems are possible through two linear actuators associated to the cables. The kinematics approach is based on the 'effective 4-bar' (E4B) mechanism, in order to stepwise adjust the system joints to the desired values [43]. All internal joints of the planar linkages are equipped with brakes (e.g., electromagnetic, hydraulic or pneumatic brakes). Accordingly, four joint variables of each actuated linkage are determined in each reconfiguration step for the reduction of the system to a 1-DOF mechanism, based on an off-line planning procedure. In each step, one different angle is adjusted to the desired value and then remains locked until the overall reconfiguration is completed, i.e., the system obtains its target configuration. Based on the particular hybrid configuration of the structure, motion planning requires in each step, two consecutively unlocked joints, or an even number of locked joints between the two unlocked ones, in such a way that the cables actions do not compete with each other. In addition, an upper limit of $175^{\circ}$ of any unlocked joint angle should avoid infeasible sequences. Throughout the reconfiguration, only slow motions are involved and inertial effects are negligible. Different feasible motion sequences are possible and a favorable one may be selected, based on specific kinematics and static response criteria. Once a motion sequence is selected, a control system manages in each reconfiguration step the operation of the individual brakes on the joints, which receive input from the position sensors (e.g., optical encoders or potentiometer-type sensors) installed on the joints. Application of the specific reconfiguration approach to the spatial structure involves coordinated shape adjustments performed on each individual actuated planar linkage. In the case of nonsymmetric reconfigurations among the planar linkages, the control system may also coordinate the reconfiguration of the overall structure by considering the relative motion of the horizontal members of the spatial system. The kinematics approach requires a minimum number of actuators, positioned on the ground and detached from the body of the main structure. In this way, minimum selfweight is preserved, since no actuators need to be moved about during the reconfigurations of the system, yielding also better energy performance.

The building envelope should enable lightweight of the material, structural efficiency, and have exclusive elastic deformations during transformation, without stress interactions with the primary structure. In addition, the envelope structure is required to be flexible in order to accommodate for cases of dissimilar configurations assumed by any adjacent actuated multi-bar linkages. In the specific example, a double layer of THV-membranes, Terpolymer 
Fig. 6 Building envelope in a symmetric and nonsymmetric structure configuration
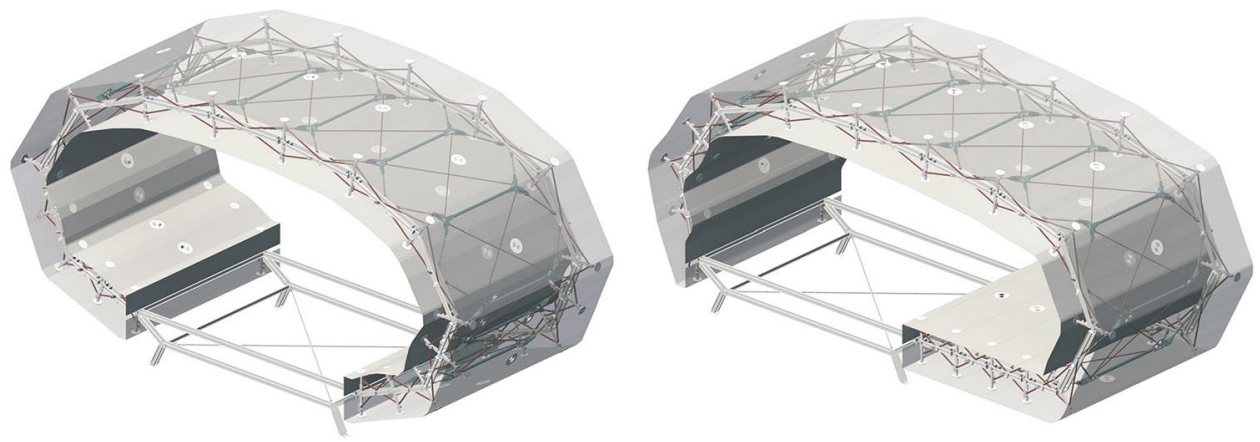

of Tetrafluoroethylene-Hexafluoro-propylene-vinylidene fluorid, is to be supported on a dedicated secondary adaptive structure rather than being directly affixed to the members of the primary structure, Fig. 6 .

\section{Spatial Bar linkage structure}

The design of an adaptive pavilion for a temporary aerospace and robotics exhibition aims at exploring the potential of a kinetic system in adjusting its shape in response to variable functional needs and external weather conditions. Specifically, the problem task refers to a temporary building suitable for easy and fast assembly, also capable to expand its floor area from 60 up to $120 \mathrm{~m}^{2}$. The 'Medusa' pavilion was inspired in its lightweight structure by the jellyfish and crystallize concepts of adaptability and transformability, Figs. 7, 8 . The principal design concept refers to a structural system capable to perform multiple configurations and enhance the spatial experience of the visitors. In particular, three scenarios are addressed in this design project. Accordingly, a
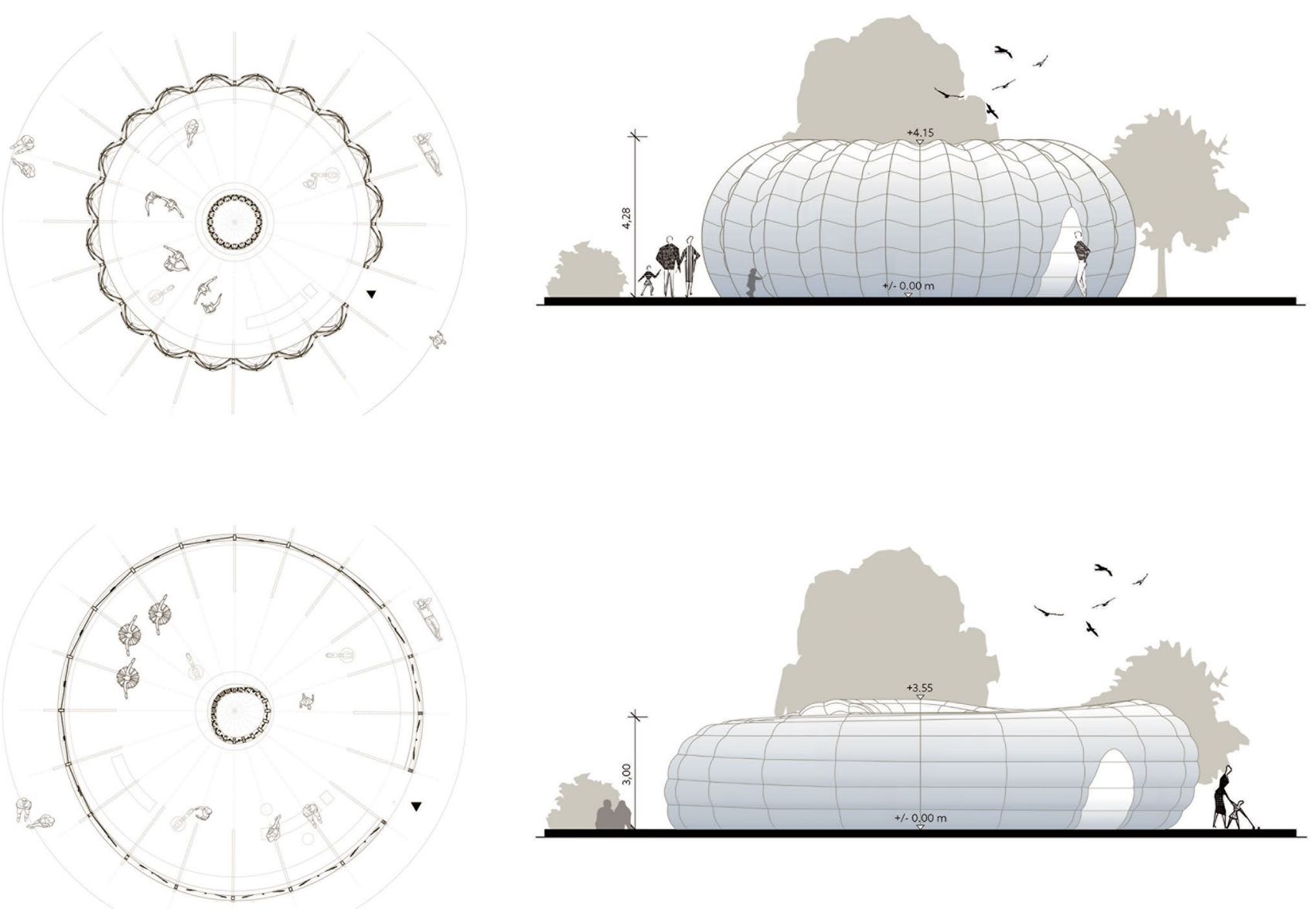

Fig. 7 Contracted and expanded building configuration in plan and elevation [L. Oestringer and M. Kip] 
Fig. 8 Contracted and expanded building configuration in section view
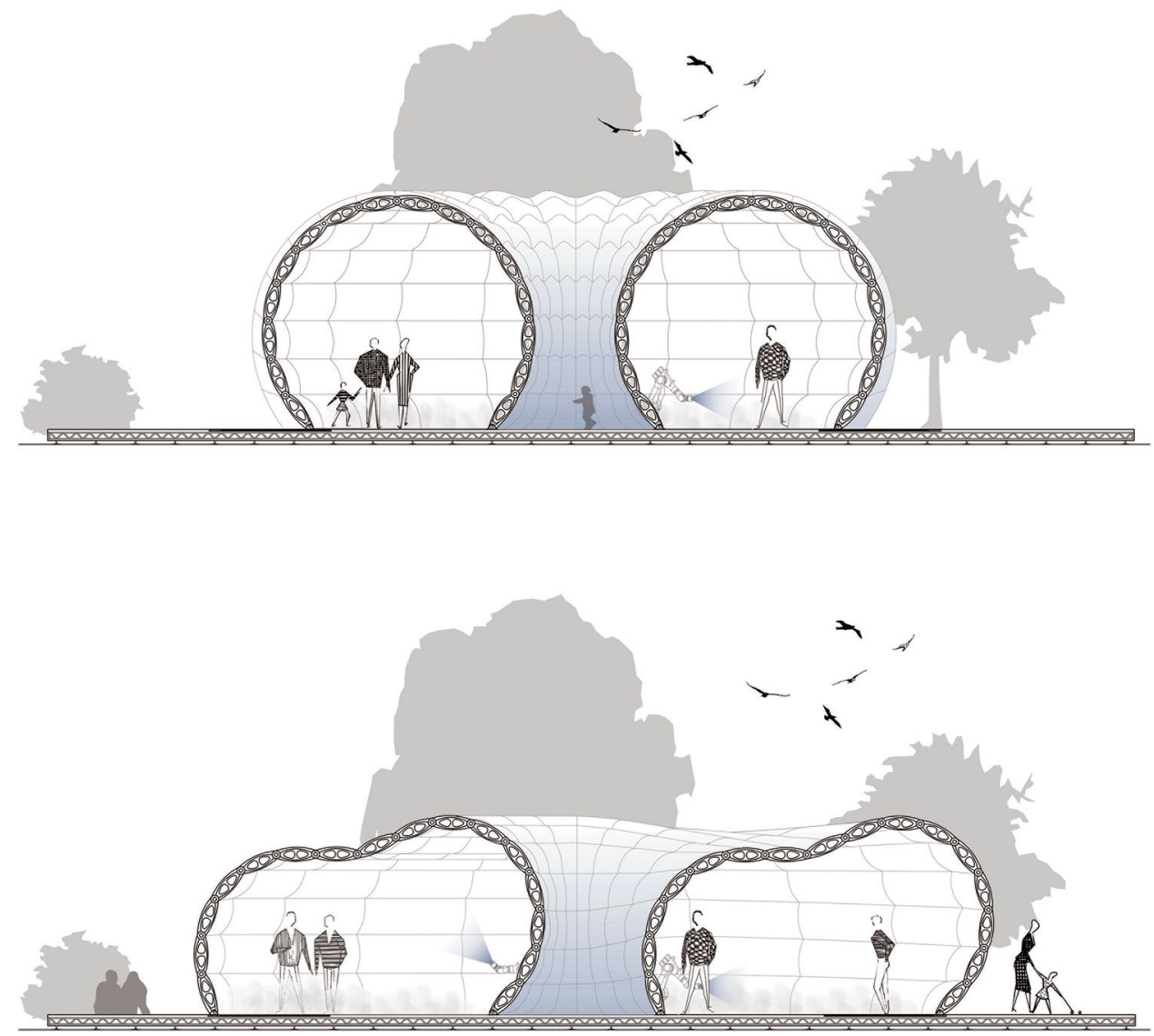

wider space for social interactions, seasonal transformability and accommodation to different climate zones is provided.

The primary arch-shape structure consists of radial planar bar linkages of sixteen rhomboid aluminium elements with dimensions of 600/200/100 mm. Figure 9 illustrates the structural system and the envelope of the proposed pavilion in two configurations. To enable transformation of the individual linkages, the effective crank-slider kinematics mechanism is applied as a multistep procedure through a linear motion actuator, which is associated with a sliding block connected to one of the supports [26]. In each step, the system is reduced to a 1-DOF mechanism through selective release of an intermediate joint, while the pin joints at the supports on either side always remain unlocked. A specific joint is adjusted through respective displacement of the sliding block in each step; from then on, it remains locked. Once the target configuration has been obtained, i.e., all joints of the system are correspondingly adjusted, the actuator locks in place by applying all the brakes. Following a preliminary motion planning, the geometric path planning of discrete motions provides a motion sequence of valid reconfiguration steps. With a span of $3.2 \mathrm{~m}$ in the initial position and $4.9 \mathrm{~m}$ in the target position, the structural system succeeds to accomplish its initial aim to contract and expand its floor area.
In the specific design, the stepwise shape adjustments of the system are controlled by a continuous cable of variable length, interconnecting the supports. A secondary $\mathrm{X}$-bracing system of bending-active members connects the bar linkages in the periphery and provides stability to the tensile envelope, while it is capable to follow the shape adjustments of the primary structure according to its low friction coefficient.

\section{Hybrid Scissor-like elements}

The pavilion presented in Fig. 10 serves as a place of convergence of a closed and open exhibition. The pavilion is capable to meet the functional needs of the exhibition, as well as to accommodate to different weather conditions by changing its configuration. Moreover, the pavilion is conceived as an autonomous building making use of solar power and generating its own energy. Inspired by the aerospace industry, the origami solar panels are foldable and adjust their opening factor, predominantly based on visual comfort and solar radiation criteria. A focal point of the design project was the creation of an interactive building enhancing communication with its environment and visitors.

The primary structure imitating centipedes recalls the design of a building with a multi-legged envelope. 
Fig. 9 Structural system in its initial position and target position
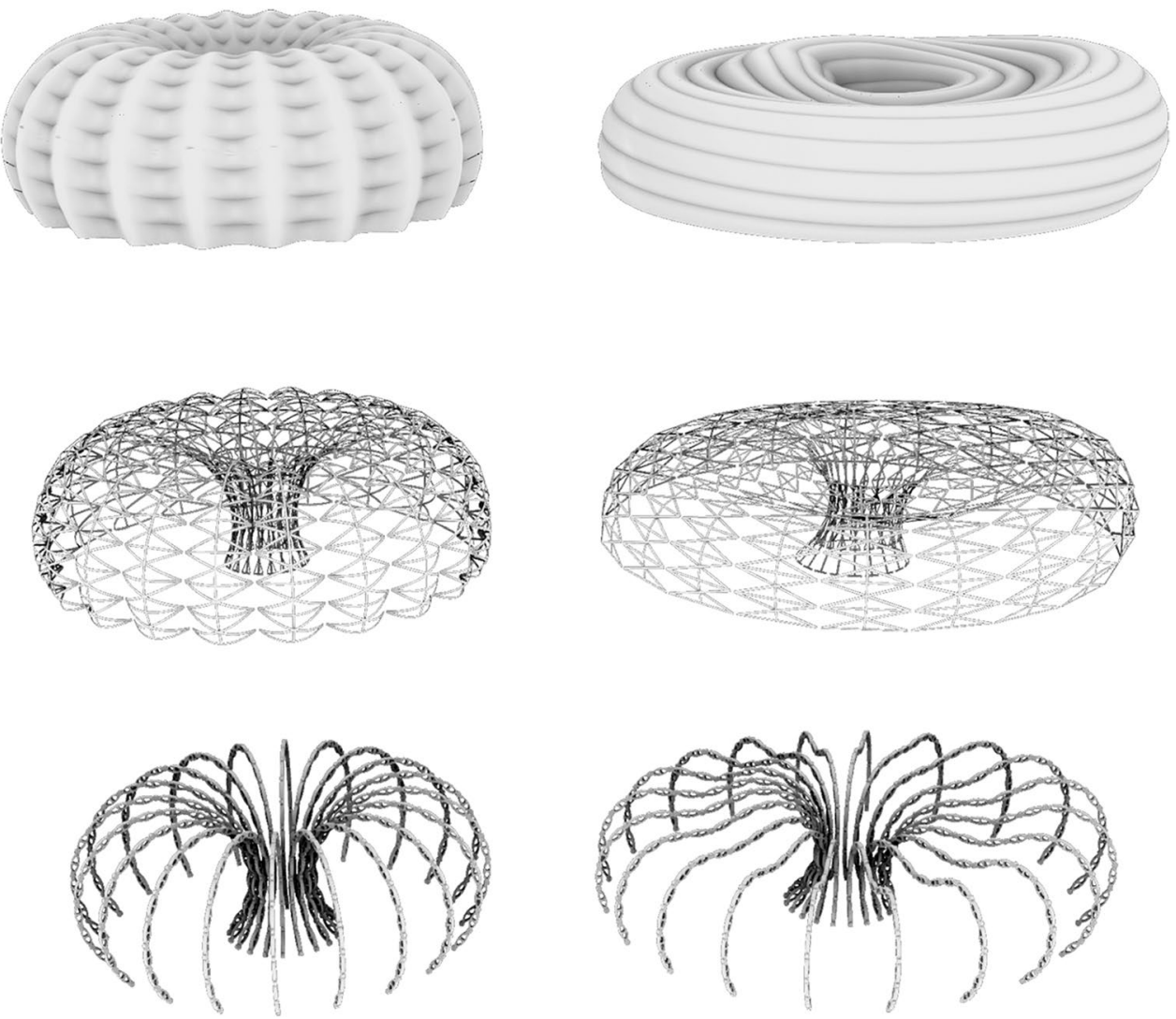

Accordingly, eighteen pairs of arch-like scissor-like elements interconnected through continuous cables of variable length comprise each side of the building. At midspan, the elements are connected to a longitudinal beam supported on diagonal columns, Fig. 11. Sliding of the diagonal members supports in opposite direction and releasing of the continuous cables of the scissor-like elements induces an increase of the width of the pavilion at the base from 7.5 to $9 \mathrm{~m}$. Further nonsymmetrical cases refer to the transformation of the pavilion space from a closed to an open one. The kinetic structure investigated in a small-scale model is shown in Fig. 12.

\section{Hybrid bending-active plates}

The Spiral Pavilion is inspired by the Fibonacci spiral, as well as the elastic behavior of flexible elements that generate new dynamic spaces and forms. The spiral typology provides
Fig. 10 Perspective view of the building [M.H. Dao]

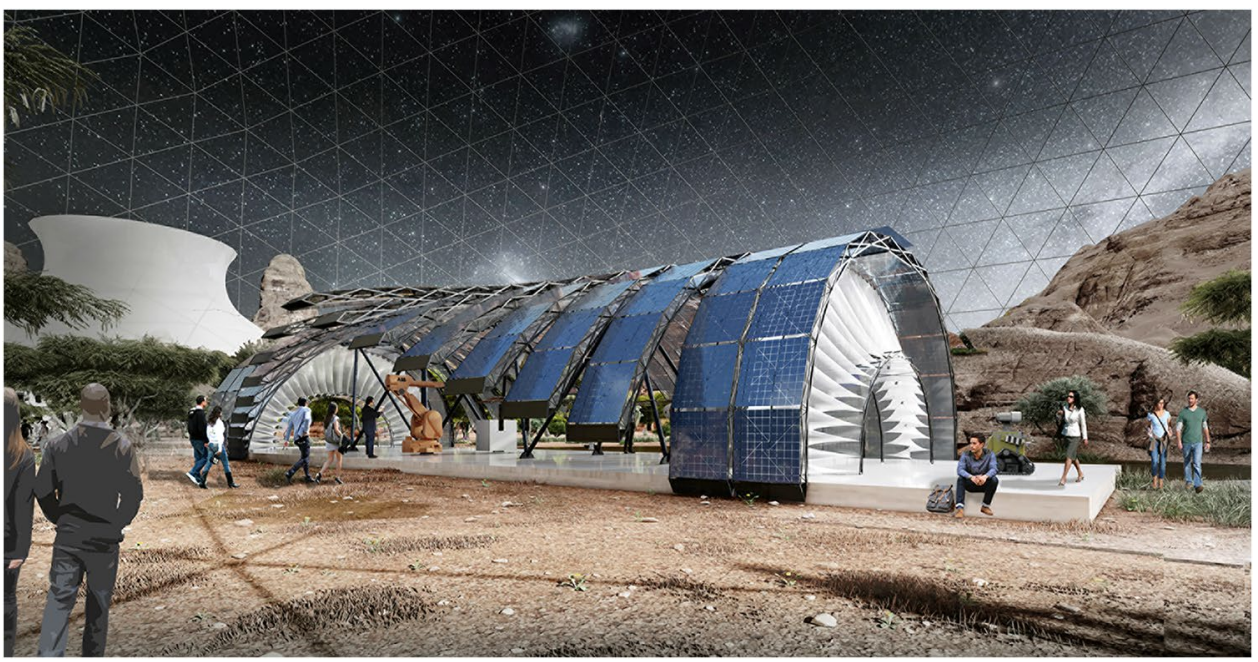


Fig. 11 Structure composition
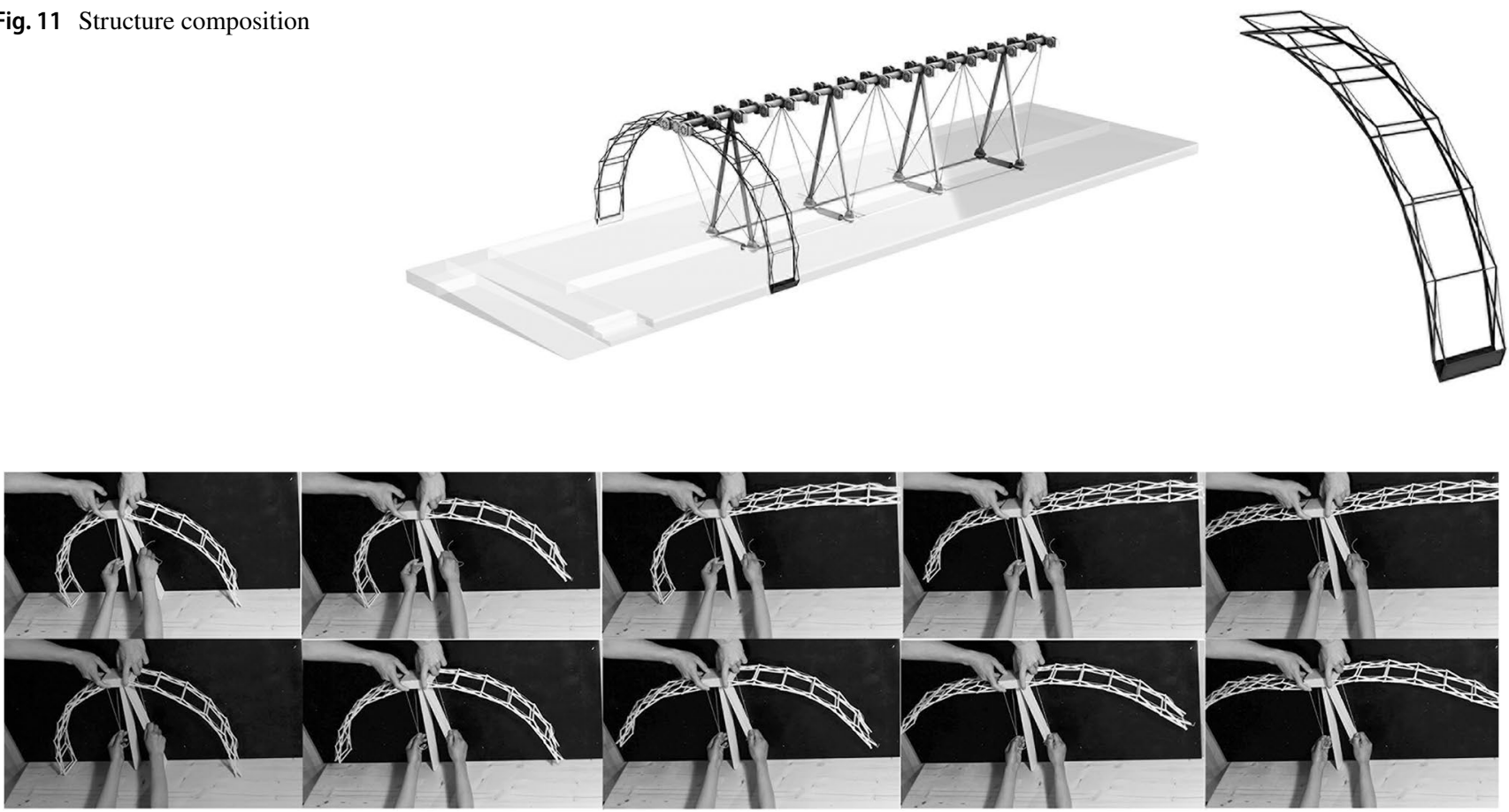

Fig. 12 Small-scale model of the structure illustrating the motion of the hybrid scissor-like elements

a pavilion that transforms its shape through hybrid bendingactive plates, while enhancing various expressions of the exhibition and the interaction with the visitors. Three scenarios implemented in this design project refer to a closed, semi-closed and open exhibition, hosting a digital, physical and interactive exhibition respectively. Shape adjustments of the building predominantly refer to the interaction with the visitors and the sun position. As indicated in Fig. 13, the higher the number of visitors, the wider is the span of the pavilion. In addition, a playful light performance takes place inside the pavilion, while creating an interplay of light and shadow during the exhibition based on the cut-out patterns on the envelope.

The spiral structure consists of arch-shaped bamboo members covered by bamboo thatch, Fig. 14. The transformable shell travels on a double-wheel track, in order to generate the shape adjustments and enable different spatial experiences. Along the arch, five $\mathrm{V}$-shaped openings are evenly distributed and responsible for control of the light transmission to the indoor spaces. An increased light transmission factor is enabled when the bending-active elements are contracted. Thus, different variations of the openings are created based on the transformation of the bending-active plates. A folding membrane is installed on the openings, in order to accommodate the different reconfigurations of the primary structure. Moreover, the pavilion projects aspects of adaptive and energy-autonomous buildings to exploit capabilities and technological advancements of human-powered floor tiles.

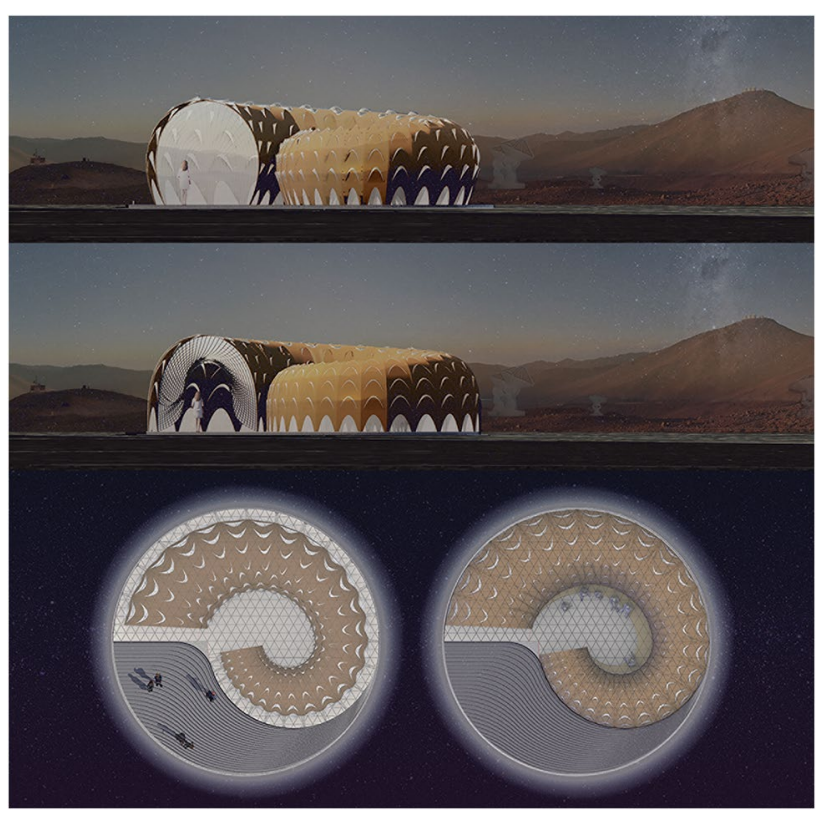

Fig. 13 Elevations and top views of the building in an extended and compact configuration [B. Negokool and J. Lu] 


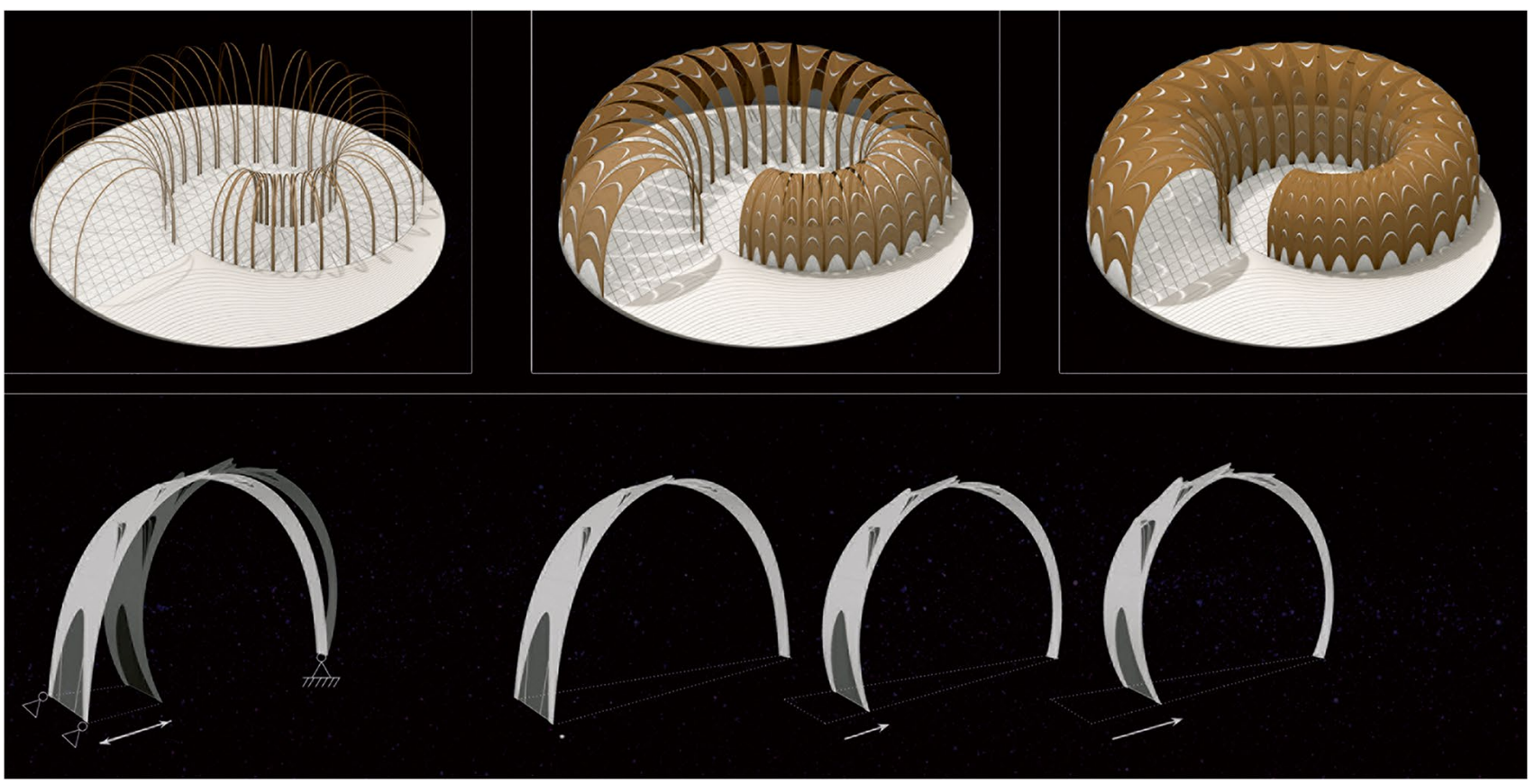

Fig. 14 Structural components and hybrid-bending active plate in different motion steps

\section{Coupled Scissor-like elements and hybrid bending-active members}

The design of a smart city unit prototype involves temporary activities that may be hosted within and renewable energy provision within the urban fabric, Fig. 15. The unit consists of two floors with autonomous kinematics. A shell unit on top of a deployable central mast follows through its own rotations, the position of the sun in collecting the solar radiation. Expandable steel diagonals in pairs that constitute scissor-like elements are supported on the mast and interconnected through vertical cables of variable length and bending-active members. The diagonals are additionally, horizontally interconnected through peripheral circular members. The bending-active members are activated by the vertical cables for their respective elastic deformations during the transformation process of the unit that in turn induces respective modification of the relative angle of the scissorlike elements. Shortage of the cables' length induces bending deformations to the elastic members and corresponding height reduction of the associated structure, while release of the cables enables the elastic members to decrease their curvature and correspondingly increase the height of the structure. The linear motion actuators associated to the vertical cables in both floors of the unit are placed on the first floor. Textile membranes connected to the bending-active members, define the shell of the unit's functional spaces. An expandable floor system follows the motion through respective transformations. Thus, the building units act as a living

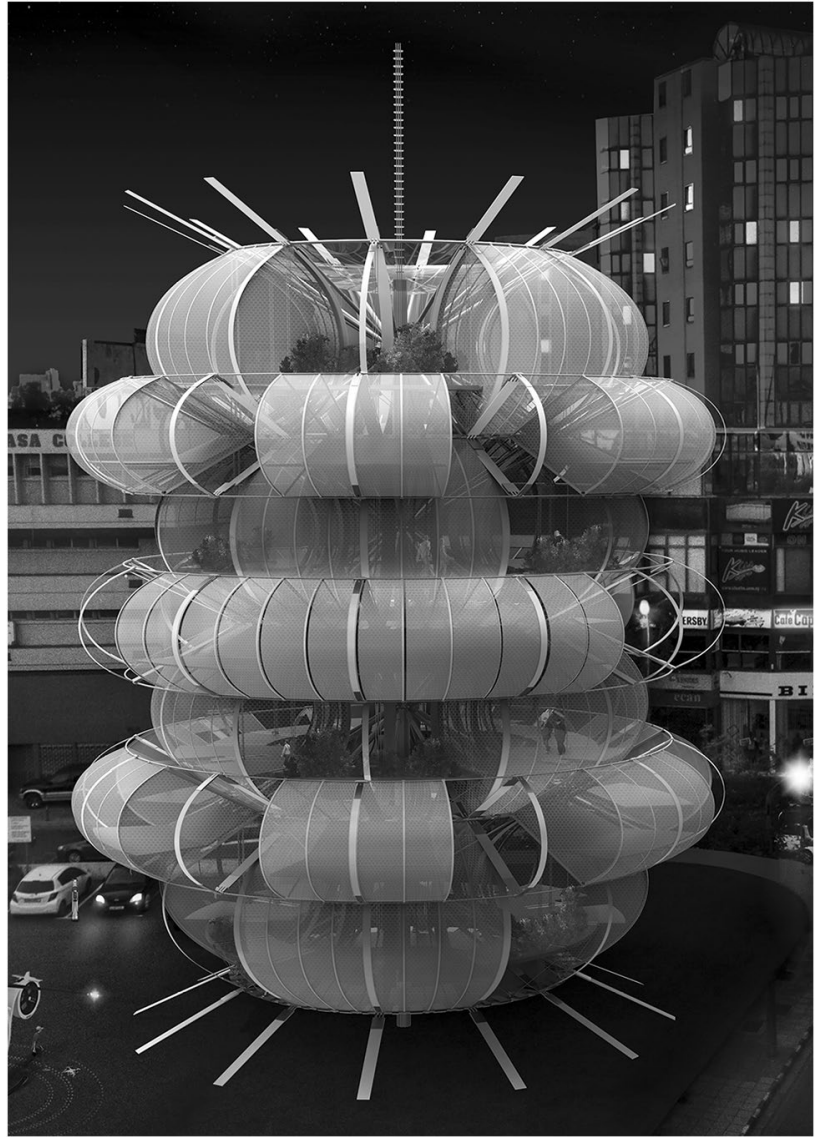

Fig. 15 Perspective view of adaptive building Unit [S. Kyprianou] 
organism that responds continuously to the sun movement. In doing so, all individual components interact: the units' shape, space, boundaries and the users' activities.

The bending-active members of GFRP (glass fiber reinforced polymere) possess appropriate geometrical slenderness in the deformation direction and material properties of low elastic modulus and high strength, and are able to undergo reversible elastic deformations. In achieving active shape and deformation control, hybridization of the members with cables of variable length has been applied as presented in [16]. Preliminary investigations on the deformability of the bending-active members have been contacted based on physical small-scale models, followed by parametric-associative digital modelling, Fig. 16. While the hybrid modular systems investigated possess enhanced deformability, further applications may extend from single to multi-segment configurations [29]. Thus, a design and nonlinear numerical analysis process would be further required, which needs to consider all stages of development, and the residual stresses developed in the elastic members. The design of the structural members based on the modularization of the structure and its components, aimed at providing clarity and readability of the load-deformation behavior and corresponding detailing of the connections, Fig. 17.

\section{Pneumatic members}

Inspired by digital art, choreography and robotics, the pneumatic pavilion hosts an interactive exhibition space that adapts in size to the respective number of visitors. Thus, the pavilion itself also becomes part of the exhibition. The realization of a tunnel typology through a pneumatic envelope and support structure contributes to a new perception of pneumatic structures. A snake-like tube formed by horizontal oriented air-cushions allows different possible configurations with an indoor area of 60 up to $120 \mathrm{~m}^{2}$, Fig. 18. The envelope consists of 40 air-cushions linearly interconnected in the transverse axis. Each module consists of two glass fiber strips that are connected through the linear pneumatic actuators. The effective width of each module is $19 \mathrm{~cm}$, while the maximum width extends to $34 \mathrm{~cm}$. The building envelope consists of an ETFE, ethylene tetrafluoroethylene, cushion system in support of the design of a lightweight structure that actively changes its shape.

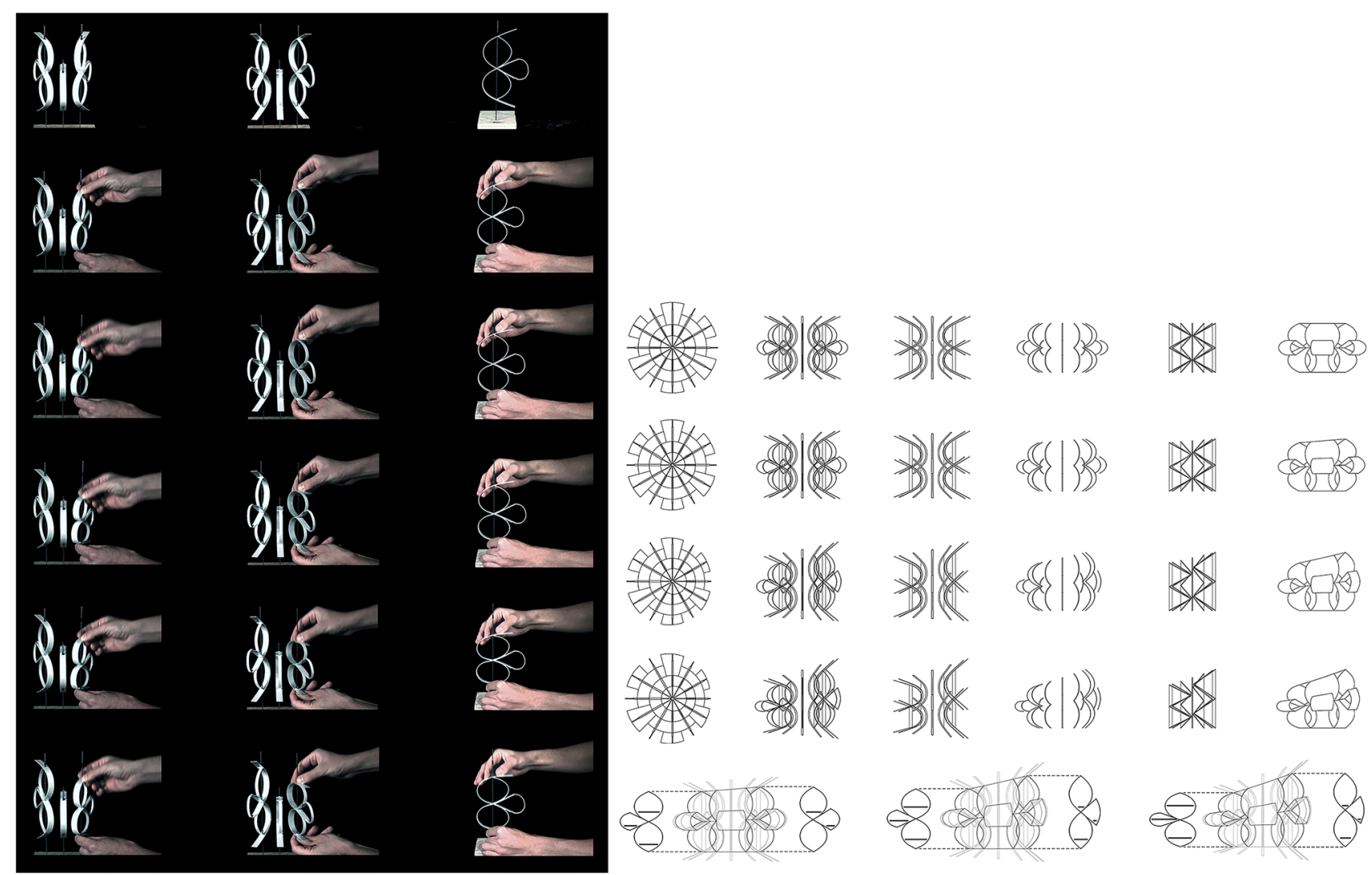

Fig. 16 Bending-active members deformability studies through physical modelling and parametric-associative modelling 


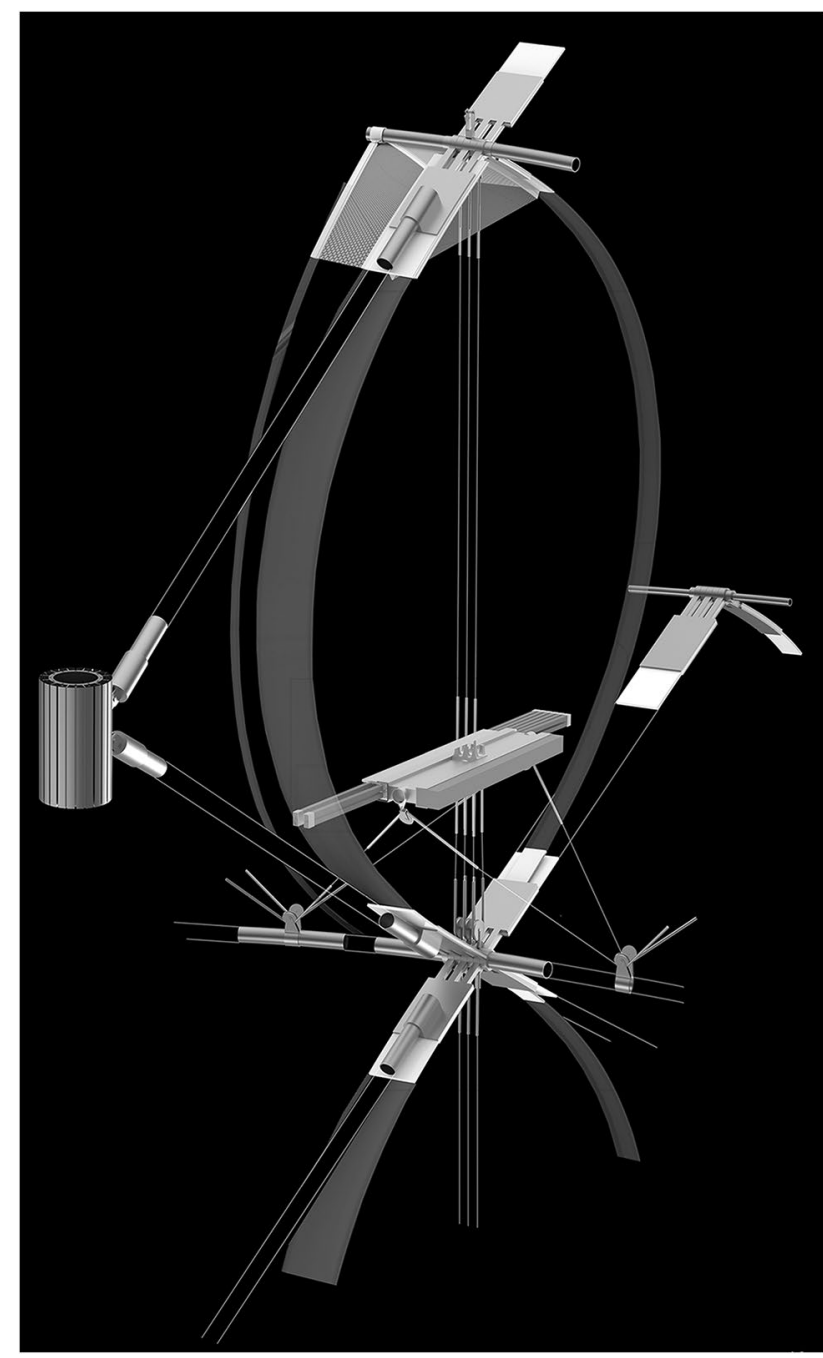

Fig. 17 Isometric view of structural components design
To control the building shape and indoor area changes, a system of sensors and a pneumatic air supply are applied. All technical systems are housed within the floor of the structure. As the individual longitudinal chambers of the air-cushions expand in width, their height decreases and the base area of the pavilion increases, Figs. 19 and 20. The behavior of the air cushions during shape changes was investigated in a parametric simulation study with the software program Rhino/Grasshopper. Despite related technological advancements and the 3D dynamic computational design methods available so far, the potentials of pneumatic structures have yet to be expanded and enhanced in a more creative and innovative approach in the early-stage of the architectural design. Advanced computational modeling methods can be used as simulation and design tools in the field of pneumatic structures to gain new scientific insights and to advance synergies between research and industry.

\section{Conclusions}

Contemporary technological advancements and constant societal changes have increased the significance of transformability relevant to various scientific and engineering contexts, including robotics, mechanisms, aerospace, manufacturing systems, computing, as well as architecture. In particular, transformable building structures enable morphological variability and are expected to significantly contribute to the sustainability of our built environment. A new generation of responsive building structures envisages to adapt to changing functional, loading, or environmental conditions. While integrated architectural design involves an integrative development of related architectural parameters, computation enables meanwhile common platforms of digital design and numerical analysis processes of investigation and research. Such interdisciplinary design-driven research is considered significant in complementing the integrated

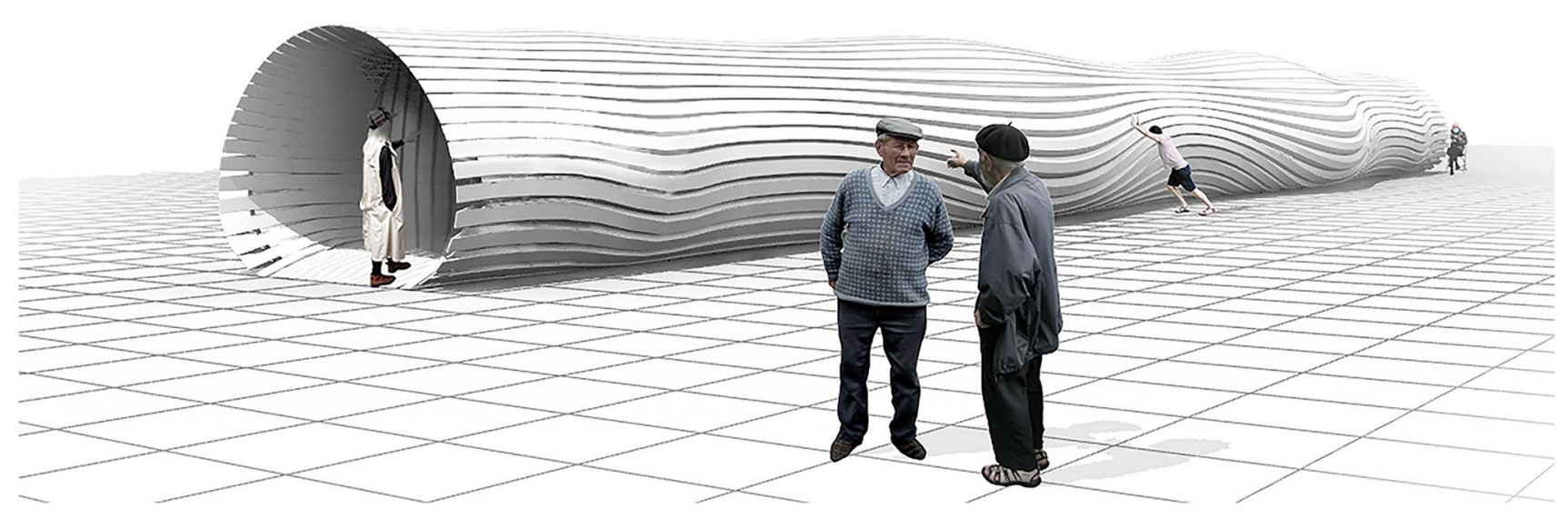

Fig. 18 Perspective view of the pneumatic building [L. Ritter and L. Frisch] 

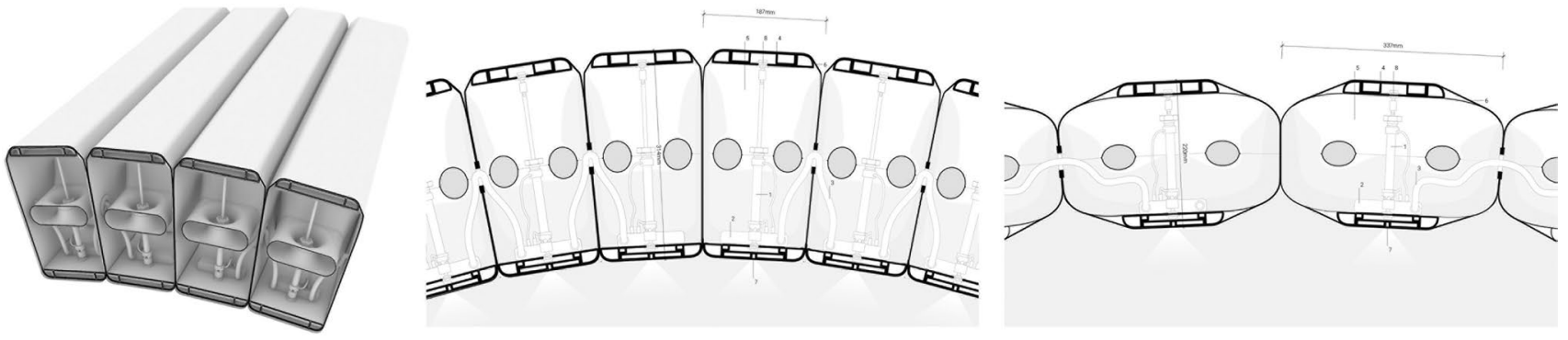

Fig. 19 Pneumatic structure with integrated linear pneumatic actuators connecting the air-cushion layers to control the width of the longitudinal air-chambers

design process through coordination and exploration of discipline-specific information from early stages of the design, and achieving efficiency and technological innovation. Given the novelty and complexity inherent in the planning of transformable buildings, close interdisciplinary cooperation within an integrated context of the development comprises a prerequisite of related technological implications within the design, as well as the provision of corresponding technology-driven identification characteristics in the architectural outcome with regard to the capacity to transform, respond and adapt to external stimuli.

The design projects presented in the current paper reflect the design methodology of integrated interdisciplinary design of transformable buildings applied by the authors at University level. Consideration of aspects of transformability already at the preliminary stage of the development, has provided a field of interdisciplinary experimentation and research towards the development of new kinetic system typologies with advantageous operational characteristics. The concepts proposed derive from the design vision of the buildings to be transformable, also reflected in architectural and technical terms, and further exploit the potentials offered by transformability. From a pedagogical point of view, the students gain experience on the development of their designs spanning different stages of the process applied; from the conceptual architectural design driven by transformability features, to the integration of the technical disciplines, up to the performancebased interdisciplinary development of the kinetic structures. The final proposals emphasize on different related aspects of transformability as set by the students and supervising teams in the first place and throughout the development. These may refer to the structural composition and control elements integration, the kinematics and motion planning, as well as the performative character of the architectural outcome. Future work includes the development of integrative computational design and numerical analysis approaches for the design of transformable buildings. While integrated and performance-based design are closely interrelated with advanced research on transformability at system and element level, further related research activities include among other, the development and investigation of hybrid structure prototypes in terms of static and kinetic operability, control efficiency, and energy performance.

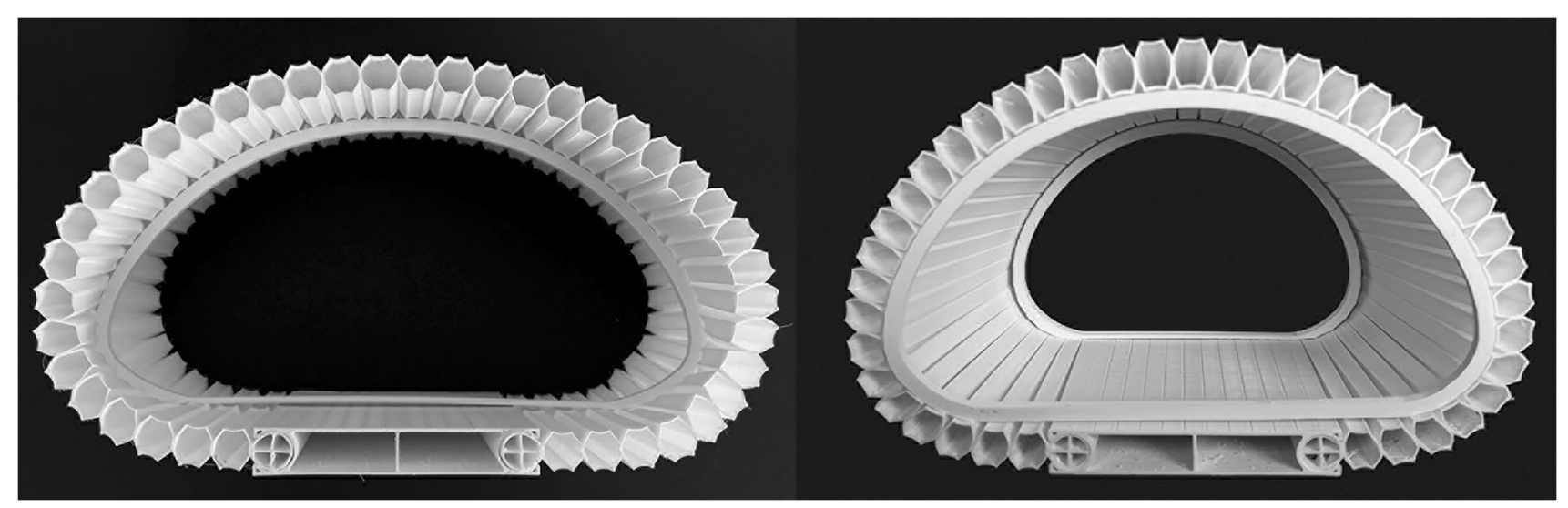

Fig. 20 3D-printed configurations of the pneumatic structure with maximum and minimum width of the air-cushions 
Acknowledgments The authors would like to thank Savvas Anastasiou, Sophia Theologou and Maria Christofi, Matthias Kip and Laura Oestringer, Man Hoan Dao, Behnaz Negokool and Jiaxin Lu, Stefanos Kyprianou, as well as Leo Ritter and Luis Frisch for the fruitful collaboration and their involvement to take on the completion of the works presented beyond their comfort zone.

Funding Partial financial support was received from the Deutsche Forschungsgemeinschaft (DFG, German Research Foundation) - Project-ID 279064222 - SFB 1244.

Data availability Not applicable.

Code availability Not applicable.

\section{Declarations}

Conflicts of interest/competing interests The authors have no relevant financial or non-financial interests to disclose.

\section{References}

1. Kronenburg R (2007) Flexible. Architecture that responds to change. Laurence King, London

2. Engel H (1999) Structure systems, 2nd edn. Gerd Hatje Verlag, Ostfildern-Ruit

3. Lienhard J, Knippers J (2013) Considerations on the scaling of bending-active structures. Int J Space Struct 28:137-148. https:// doi.org/10.1260/0266-3511.28.3-4.137

4. Zuk W, Clark RH (1970) Kinetic architecture. Van Nostrand Reinhold, New York

5. Fenci GE, Currie NGR (2017) Deployable structures classification: a review. Int J Space Struct 32(2):112-130. https://doi.org/ 10.1177/0266351117711290

6. Pugh A (1976) An introduction to tensegrity. University of California Press, Berkeley

7. Tibert AG, Pellegrino S (2003) Review of form-finding methods for tensegrity structures. Int J Space Struct 18(4):209-223. https:// doi.org/10.1260/026635103322987940

8. Escrig F (1985) Expandable space structures. Int J Space Struct 2(1):79-91. https://doi.org/10.1177/026635118500100203

9. Gantes CJ (2001) Deployable structures: analysis and design. WIT Press, Southampton

10. You Z, Pellegrino S (1997) Foldable bar structures. Int J Solids Struct 15(34):1825-1847. https://doi.org/10.1016/S00207683(96)00125-4

11. Chen Y, Peng R, You Z (2015) Origami of thick panels. Science 349(6246):396-400. https://doi.org/10.1126/science.aab2870

12. Li S, Fang H, Sadeghi S, Bhovad P, Wang KW (2019) Architected origami materials: how folding creates sophisticated mechanical properties. Adv Mater 31(5):1805282. https://doi.org/10.1002/ adma.201805282

13. Phocas MC, Christoforou EG, Matheou M (2015) Design, motion planning and control of a reconfigurable hybrid structure. Eng Struct 101(10):376-385. https://doi.org/10.1016/j.engstruct.2015. 07.036

14. Thrall AP, Adriaenssens S, Paya-Zaforteza I, Zoli TP (2012) Linkage-based movable bridges: design methodology and three novel forms. Eng Struct 37:214-223. https://doi.org/10.1016/j.engstruct. 2011.12.031
15. Lienhard J (2014) Bending-active structures. Form-finding strategies using elastic deformation in static and kinetic systems and the structural potentials. Dissertation, University of Stuttgart

16. Phocas MC, Alexandrou K (2018) On decoding the structural behavior of hybrid cable bending-active units in fastening, prestress and load-bearing state. Int J Space Struct 33(2):98-111. https://doi.org/10.1177/0266351118795338

17. Adam B, Smith IFC (2008) Active tensegrity: a control framework for an adaptive civil-engineering structure. Compos Struct 86(23-24):2215-2223. https://doi.org/10.1016/j.compstruc. 2008.05.006

18. Ganga PL, Micheletti A, Podio-Guidugli P, Scolamiero L, Tibert G, Zolesi V (2016) Tensegrity rings for deployable space antennas: concept, design, analysis, and prototype testing. In: Frediani A, Mohammadi B, Pironneau O, Cipolla V (eds) Variational analysis and aerospace engineering, vol 116. Springer, Cham, optimization and its applications, pp 269-304. https:// doi.org/10.1007/978-3-319-45680-5_11

19. Hanaor A (1998) Tensegrity. Theory and application. In: Francois GJ (ed) Beyond the cube. Wiley, New York, pp 385-405

20. Tibert G (2002) Deployable tensegrity structures for space applications. Dissertation, Stockholm Royal Institute of Technology

21. Hoberman C (1993) Unfolding architecture: an object that is identically a structure and a mechanism. Arch Des 63:53-59

22. Akgün Y, Gantes CJ, Kalochairetis K, Kiper G (2010) A novel concept of convertible roofs with high transformability consisting of planar scissor-hinge structures. Eng Struct 32:2873-2883. https://doi.org/10.1016/j.engstruct.2010.05.006

23. Akgün Y, Gantes CJ, Sobek W, Korkmaz K, Kalochairetis K (2011) A novel adaptive spatial scissor-hinge structural mechanism for convertible roofs. Eng Struct 33(4):1365-1376. https:// doi.org/10.1016/j.engstruct.2011.01.014

24. Alegria Mira L, Filomeno Coelho R, Thrall AP, De Temmerman N (2015) Parametric evaluation of deployable scissor arches. Eng Struct 99:479-491. https://doi.org/10.1016/j.engstruct.2015.05. 013

25. Christoforou EG, Phocas MC, Matheou M, Müller A (2019) Experimental implementation of the 'effective 4-bar method' on a reconfigurable articulated structure. Struct. 20:157-165. https:// doi.org/10.1016/j.istruc.2019.03.009

26. Phocas MC, Christoforou EG, Dimitriou P (2020) Kinematics and control approach for deployable and reconfigurable rigid bar linkage structures. Eng Struct 208:110310. https://doi.org/10.1016/j. engstruct.2020.110310

27. Anastasiadou I, Phocas MC (2020) Deformation control and shape adaptation of a hybrid bending-active gridshell. In: Choi C-K (ed) The 2020 Structures Congress, Structures20, 2020 International Conference on Advances in Computational Design. Seoul

28. Ferre A (2007) Patent constructions. New Architecture made in Catalonia. Actar, Barcelona

29. Phocas MC, Alexandrou K (2018) Numerical analysis and cable activation in hybrid bending-active structures with multiple cables. Eng Struct 174:561-572. https://doi.org/10.1016/j.engst ruct.2018.07.089

30. Kolarevic B, Parlac V (2015) Building dynamics: exploring architecture of change. Routledge, Oxon

31. Temmerman ND, Roovers K, Mira LA, Verauwen A, Koumar A, Brancart S, Laet LD, Mollaert M (2013) Engineering lightweight transformable structures. In: Proceeding of International Conference of Adaptation and Movement in Architecture, ICAMA 2013, Toronto, pp. 44-57

32. Hoffmann S, Barej M, Puppa GD, Hüsing M, Trautz M, Corves B (2013) Interdisciplinary design of movable structures in architecture education. In: Proceedings of the first Conference 
Transformables 2013. In the Honor of Emilio Perez Pinero, Seville, pp. 411-416

33. Fox M, Yeh B (1999) Intelligent kinetic system. MIT, Massachusetts

34. Fox M, Hu C (2005) Starting from the micro: a pedagogical approach to designing interactive architecture. In: ACADIA05: smart architecture

35. Oxman R (2008) Digital architecture as a challenge for design pedagogy: theory, knowledge, models and medium. Des Stud 29:99-120. https://doi.org/10.1016/j.destud.2007.12.003

36. Masengarb J, Rehbein K (2007) The architecture handbook: a student guide to understanding buildings. Chicago Architecture Foundation, Chicago

37. Busby Perkins + Will (2010) Roadmap for the integrated design process. BC Green Building Round Table, Vancouver. http:// www.greenspacencr.org/events/IDProadmap.pdf. Accessed 25 Aug 2021

38. Mallory-Hill S, Preiser WFE, Watson CG (2012) Enhancing building performance, 1st edn. Wiley, Chichester
39. AIA (2007) Integrated project delivery: a guide. The American Institute of Architects, Washington

40. Leistner S, Honold C, Maierhofer M, Haase W, Blandini L, Sobek W, Roth D, Binz H, Menges A (2020) Research on integral design and planning processes for adaptive buildings. Architect Eng Des Manag. https://doi.org/10.1080/17452007.2020.1856031

41. Picon A (2003) Architecture and the virtual. Towards a new materiality? Thesis, Wissenschaftliche Zeitschrift der BauhausUniversität Weimar, 3

42. Zeiler W (2011) Integral design: to combine architecture and engineering for a sustainable built environment. In: International conference on engineering design (ICED11), Kongens Lyngby

43. Matheou M, Phocas MC, Christoforou EG, Müller A (2018) On the kinetics of reconfigurable hybrid structures. J Build Eng 17:32-42. https://doi.org/10.1016/j.jobe.2018.01.013

Publisher's note Springer Nature remains neutral with regard to jurisdictional claims in published maps and institutional affiliations. 